\title{
Ethical and Traditional Concerns in Contemporary Japanese Design
}

\author{
Parisa Yazdanpanah Abdolmaleki \\ MSc, Department of Architecture, Islamic Azad University of Hamedan, Iran \\ E-mail: Yazdanpanah222@gmail.com
}

Ehsan Daneshfar

MSc student, Department of Urbanism, Islamic Azad University

Science and Research Branch, Tehran, Iran

\begin{abstract}
Similar to its old history, Japan has a rich traditional and ethical Architecture. Based on these tenets and ethics, different concepts and spaces are formed through the time, as now Japan's ethical and traditional design ideas has its standard principles. Linking the present and the past has always been a momentous criterion in the countries with an old rich Architecture. This fact is indeed important in Japan due to the blend of ethics and religions with peoples` life. Through this idea, three Japanese Architects, Kenzo Tange, Fumihiko Maki and Tadao Ando-who are the only Japanese pritzker prize winners-have well, noticed the need for linking the country's traditional and ethical Architecture criteria with the contemporary Architecture. So, analyzing such projects of these architects prepares a good basis to find out the quality of how traditional and ethical design ideas crystallize in the works of contemporary Japanese architects.

The research method for this article is a comparative analysis between the architects ' particular projects and Japan's ethical and traditional design ideas, formed through the history of architecture in this country. The contents of this article rely heavily on three bases: 1) study of the historical documents concerning the ethical and traditional design concepts in Japan. 2) The consultancy of leading experts on Asian traditional constructions and ethical architecture specialists from Azad Universities in Tehran. 3) Comparative analysis between the ethical concepts applied in different contemporary works.

The results show that the contemporary architects have had good bases for presenting the traditional design concepts as standard principles are all formed in the architecture of Japan today. Meanwhile, it seems that Maki and Ando are more likely to have a conceptual look at Japan's traditions while Tange has a more formal viewpoint. Chronological analysis of the architects' projects shows that despite, all the three architects were impressed by the works of le Corbusier, they were successful to keep contacts with Japan's traditional design concepts.
\end{abstract}

Keywords: Ethical-traditional concerns, Japanese design, Tange, Maki, Ando

\section{Introduction}

A reversion to traditional architecture and the quality of using its principles in contemporary architecture has always been a momentous criterion in the countries with a rich architectural record. Different theories and viewpoints are presented on the quality of linking the traditional and contemporary architecture, through the history. In classic admirers' viewpoint, the association with the past architecture should be of an imitative kind. Modernists ignore whatever related to the past and history while in the works of avant-garde postmodernists the issue has changed to an imitative and non-unique relationship.

It seems that the need for having contacts with the past, in the countries where architecture has a unique association with peoples' ethics and traditions, is of a more importance as it has got a momentous role in forming the identity of people. Japan, is a country with an old background in traditional and ethical architecture. Different concepts and spaces are formed in coordination with these traditions and ethics through the history. In Japan's historical architecture, ancient ethics and religions have had an important role in creating the architectural spaces. In fact, the blend of these themes with the peoples' life, in the history of Japan, has made the Japanese architects concern about the concepts of traditional and ethical architecture.

It seems that among Japan's contemporary architects, Kenzo Tange, Fumihiko Maki and Tadao Ando have had a better attempt to use the traditional concepts in their works. These architects, as the only Japanese winners of the 
international Pritzker prize, have had different attempts on crystallizing the traditional and ethical concepts in their projects. Hence, on one hand, analyzing these projects of the architects, describes the position of the traditional Japanese architecture principles, on the other hand it represents a good pattern for using the traditional design ideas in the contemporary architecture and as a result to be able to contact with the past criteria.

To achieve the above objective, this article firstly analyses the characteristics of different religions in Japan and the related principles and ethics. Representing the principles of Japan's architecture traditions, we then analyze the particular projects of the mentioned architects in comparison with the traditional design principles to describe how they are crystallized in their projects. Meanwhile, to have a more certain conclusion the architects' intellectual bases and their contemporaneous ideologies in the architecture of the western world- which could have influenced them- are as well considered.

\section{Japanese Religion}

Despite not having large geographical extents, Japan has always been a place for the expansion of different religions. Looking back through the history of Japan, we find the traces of different sects and religions. The oldest religion in Japan, known as prehistoric religion, is of the year 6000B.C. This early religion which has a special position among the Japanese is usually studied in three historical periods:

1-The first period entitled Jomon (6000B.C-250B.C) discusses the relationships between religion and fertility.

2-Yayoi, as the second period (250B.C- 225A.D) highlights the ethical importance of burial and dead bodies. In this period we also see the traces of the burial rites with urns and cruses.

3-From the third period entitled Kofun (250A.D- 600 A.D), there are still remains of ancient stony tombs with trenches around. (Erhart H, B, 2005)

Along these periods, some traditions formed as well. Today these traditions are known with the names of their periods.

After the prehistoric religion, the most important religions formed and broadcasted during (600-700 A.D) in Japan are as follows: Shinto, Buddhism, Confucius and Taoism. It is also needed to emphasize that, different sects of Buddhism religion as Shingon, Tendai, pure realm, Nichiren and Zen, formed and founded till 1400A.D.

If we consider the above ethics and traditions as the first period in forming the Japans religions, the second period could begin with the propagation of Christianity since the $16^{\text {th }}$ century in Japan. Since then some other religions as Tenrikyo, Soko Gakkai \& Folk religions promoted and developed in the country. It is also noticeable that in post war periods (after 1945), when the Shinto religion lost the supports of the governments, the ideas in religion liberalism and a general despondency toward religions developed in Japan.

\section{Concepts and principles of Japan`s traditional architecture}

After analyzing the religions and ethics in Japan, a more accurate look at the traditional and historical architecture of this country proves that in addition to the existing ethical and spatial principles, there are some spatial concepts which have the potential to be crystallized in different architectural frameworks, too. To make it more clear, here the architectural elements and frameworks are considered as physical instruments to express and identify the spatial, yet not identified concepts. The most important concepts are: Oku, Ma and Miegakure.

In the spatial concept of Oku, a vague, pallid covering is usually created as a stop and as something to make a mysterious space around. For instance, sometimes as we look through the obscure screens, a halo view of the outside happenings and spaces are achieved. But the access to the outside is limited due to the screens. As the result, we have an inaccessible, mysterious existence. There is no completely analogous word term in English. $O k u$ connotes a mysterious depth or symbolic, unattainable center; it refers less to a measurable distance than to a metaphysical dimension, and can apply on many scales, from city to shrine. To describe the concept, Maki's 1979 book Miegakure Suru Toshi referred to the paradigmatic Japanese village located along a river valley at the base of a forested mountain.2 For the villagers, the mountain is imbued with a spiritual life, but it is not a place or a spirit that can be known. The mountain is a mysterious part of the collective unconscious, evoking a mystery that is neither sinister nor benign. It only lurks, and its presence constantly reminds the villagers that something unknowable lies beyond. This concept is also used in Japanese architecture as obscure and vague screens are used in the façade of the buildings. In this case the mysterious existence seen behind the screens is close to the spatial concept of oku. (Levitt, 2005, 1-5). A second concept that has influenced the contemporary Japanese architecture is $m a$. This is best understood as relational space, or the space between things. A The New York Times article once reported that when researchers asked schoolchildren from America and Japan to describe the contents of a fish tank, the American children described the individual fish, whereas the Japanese children 
described the relationships between them. This propensity is the basis of ma. (Goode, August8, 2000) Ma is usually defined as an experimental place, which provides us with a mysterious feeling. (Jodat, 1996, 11) In the Japanese spatial concept of Ma, the word Space, has always had the second priority because the space which is only physically defined cannot provoke one's imagination, resulted from the human experience of the place. (Jodat, 1996, 35) Ma is more an imaginary concept rather than being physical and in fact, Japanese perception of the word Place is similar to the western understanding of space. (Jodat, 1996, 44) Utilizing the concept of Ma in architecture could be considered as an attempt to visually connect the vacant and median spaces of the buildings. For instance, by using trellises and lattice screens at the sides of the passages, to visually connect them. We can also have this experience with a bigger scale, in cities. In this case the ones in the buildings, looking out through the screens have a visual experience of the continuous space. (Levitt, 2005, 1-6 \& Maki, 1994, 265-67)

Closely related to $o k u$ is another Japanese expression, miegakure. Literally "to glimpse something that is hidden," such as the moon passing behind clouds, it is concept that embodies both the ephemeral and ambiguous. It can be explained as the abstraction of an experience completed only in our minds. For instance, it is the white undergarment beneath the collar of a kimono that seduces the viewer into imagining what lies beneath - or, as Maki frames it for a Western audience, the lace negligee that hints at the shape of a naked body, without revealing it. Maki also describes the elements of Japanese cities as veiled. Thus, screens may allow cursory glances to the interior of a store while preserving the privacy of the patrons therein. Meanwhile, inside, the visitor finds refuge from the chaotic city while still being connected to it through the slits in the louvers. (Levitt, 2005, 1-6)

In addition to the mentioned concepts, the traditional and ethical architecture of Japan has some other principles and specifications in using spaces, materials, details and the quality of contacting with the outer spaces.

\section{The reflection of Japanese spatial customs and ethics in Japan`s contemporary Architecture}

The rich traditional and ethical architecture history of Japan, which could be explained as a combination of different spatial concepts in relation with the quality of using materials in harmony with the environment, has made the Japanese contemporary architects to consider the traditional concepts as an original design reference. Herein, three eminent architects, Kenzo Tange, Fumihiko Maki and Tadao Ando have more referenced to the past architecture of their country. Thus, analyzing this class of the architects ' projects clarifies the methods; each has faced, in using the traditional architecture customs.

Meanwhile, discussed themes on the background of religions in Japan and their traditional architecture principles provide the required bases to analyze such projects of the architects.

\section{Kenzo Tange}

As with so many other aspects of Japanese culture and society, the jump to modern technology brought a quite noticeable leap in architecture as well. The need to rebuild Japan after world war $\|$ proved a great stimulus to Japanese architecture. Among this, Kenzo Tange, one of Japan`s most famous and influential post-war architects managed to fuse traditional Japanese architecture with scientific and technological advancements. Tange was notable for infusing Japanese aesthetic ideas into starkly contemporary buildings, returning to the spatial concepts and modular proportions of tatami (sleeping mats), using textures to enliven the ubiquitous Ferro concrete and steel and integrating gardens and sculpture into his designs. He used the Cantilever principle in a pillar and beam system reminiscent of ancient imperial palaces; the pillar- a hallmark of Japanese traditional monumental timber construction- become fundamental to his designs. (AIArchitects.April4, 2005) Another theme of his infusion is in using the Japanese traditional concept of haphazard discipline in his designs. This haphazard discipline, called "Arare" in Japanese traditions is used in recent ages of tea-gardens. The position of the buildings and the arrangement of macadams in such spaces, are used by Tange and his partners in design of Tokyo. (Jodat, 1996, 12-13) we can say that Tange was of those post-war architects who made a great attempt to fuse traditional architecture in to starkly contemporary buildings. Today, his works are considered at the crossroad of contemporary and traditional architecture. From his pint of view, traditions must be like a catalyst that disappears once its task is done. (AIArchitects, April4, 2005; Suzuki, 2007) Tange has often pointed out the following six features as typical of Japanese space:

1) value placed on simplicity and clarity

2) use of standard modules such as Tatami mats

3) absence of decoration

4) use of beautiful natural materials 
5) right and left asymmetry

6) Harmony with nature.

These elements of Japaneseness Are often thought to be condensed in the architecture associated with Shinto shrines, residential buildings and teahouses. Tange classified the six characteristics of Japanese space mentioned above into two streams. He identified the first three features with what he called the "Yayoi tradition", deriving from Shinto shrines, residential buildings and teahouses, and latter three were derived from the "Jomon tradition," displaying the dynamism and vitality of ordinary people. For Tange, these traditional expressions constituted the essence of "Japaneseness." Nonetheless, his notion of "Japaneseness" in architecture was not monolithic but derived from conflicting "Jōmon" and "Yayoi" strands in Japanese cultural history. In this way, postwar Japanese architects were able to build up concepts of "Japaneseness" formed in the prewar years.(Yu kishi,2006)

\section{Sample projects with traditional or ethical insight}

1) Hiroshima peace memorial, 1949, Hiroshima:

The monument in the form of a hyperbolic parabolic shell, (Image no.1) brings together modern tendencies and techniques and the ancient form of Haniwa, (Image no.2) the traditional tombs of the rulers of old Japan. (Kultermann Udo, 1989, 163-5)

2) Kagawa prefectural office, 1955-8, Kagawa:

A) The office emulated in concrete the heavy, high articulated, and seismically resistant post-and-beam structures of traditional Japanese temples. (Image no.3)

B) Its ceramic Zen symbols emblazoned on the walls. (Image no.4)

C) A rock garden in the tradition of Ryoanji temple which strikes an unmistakably note in the modern idiom of reinforced concrete. (Image no.5)

D) Using exposed textured concrete.

E) Japanese ponds with sculptural stone blocks. (Time in partnership with CNN, 2008, p1-2)

\section{Fumihiko Maki}

From his point of view, although Technology tends to imply a new invention, ingenuity, almost like a panacea, but it doesn't lead us to the new utopia. He believes that in the process of decision-making, the architect is required to rely on his innate aesthetic preference for certain forms of space, but also on his ethical and traditional principles. He thinks of the form as a reduction of ethics to a question of aesthetics. He also considers lightness as a very important factor in the architecture today, and as a real concern for architects. (Architectural record symposium, feb26-28, 2004, p3-7) Maki advanced new city planning ideas based on the principle of layering or cocooning around an inner space (oku), a Japanese spatial concept that was adapted to urban needs. He also advocated the use of empty or open spaces (ma), a Japanese aesthetic principle reflecting Buddhism spatial ideas. Another quintessentially Japanese aesthetic concept was a basis for Maki designs which focused on opening onto intimate garden views at ground level while cutting off sometimes-ugly skylines (Levitt Brendon, 2005; Maki Fumihiko, Jan1993, p172). Another recurring aspect in Fumihiko Maki's designs is his masterful use of light, a quality that is further developed in Maki's works of the 1990s.

\section{Sample projects with traditional or ethical insight}

1) Gender Equality Center (GEC), 2000, Nihonmatsu:

The GEC is a multiuse community center in a small town $(250 \mathrm{~km}$. north of Tokyo).In this building, a delicate screen of aluminum and wood louvers encloses forth and fifth floors. The vertical louvers cloak a variety of functions, from seminar rooms and research labs to guest rooms. Apart from their physical performance, they reflect deep meanings rooted in traditional Japanese conception of space; Light emanating from behind the louvers hints at something within, but the screen does not allow direct visual access. (Image no.6)Thus, as he or she mounts a series of ramps and stairs, a visitor catches glimpses of the space; these mysterious spaces remind the traditional Japanese concepts as Oku and Miegakure. (To glimpse something that is hidden, as defined before). Perforated screens which create visual connection between building spaces, express the meaning of Ma As the third Japanese traditional concept that has influenced Maki's architecture). (Levitt, 2005, P1-6.Maki, 1986)

2) The Exhibition Pavilion of Tepia, 1989, Minato: 
Maki's design for the foyer of Tepia, an exhibition pavilion for new technology, explores the traditional Japanese notion of veiled space. Finely perforated metal panels are suspended from stainless steel cables to form an updated kind of Shoji screen that filters views to the city from the interior and views to the foyer from the exterior.(attempts to express the Oku concept) (Image no.7) (Levitt, 2005, P1-6 .Ishii, 1990, v. 65, no, 8-9, p. 65.)

\section{Tadao Ando}

Tadao Ando as one of the most famous contemporary Japanese architects has pursued what he calls an architecture that moves people with its poetic and creative power. (AIArchitect, April4, 2005)His numerous buildings yield intensely meaningful and didactic experiences. In so doing, Ando has engaged the discipline in the core philosophical questions on humanistic values, such as the end and purpose of creatively, or what architecture can contribute to improve the quality of human existence. Ando's effort to provide an intense architectural experience rests not only with materials but also with building form and open spaces. While visitors become familiar with Ando's floor plan, they recognize the persistent recurrence of pure geometry in these buildings. The simplicity and purity of forms and materials also support what Ando has called the nature, in particular, light ,air and water, of his architecture. Ando once commend that architecture should not be loud but rather that it should let nature in the guise of sunlight and wind, speak (Furuyama, 2005, 172). Ando's buildings often have many windows and glass bricks in their walls to let the light penetrate inside the buildings. A closed relationship between Ando's projects and Japan's traditional architecture is clearly indicated. (Like Tange and Maki's projects, as examined before) For instance central courtyards seen in Osaka traditional houses, has influenced Ando's urban design. Besides he uses large staircase and connectional bridges in open spaces to increase the sense of freedom in his projects. Ando's interest in the spatial sequence led him to explore the potential significance of vertical circulation. A staircase is, in the utilitarian sense, nothing but the means to traverse between different floor levels. In the middle of 1980s, Ando's thought about open corridors, connectional bridges and central courtyards became widespread in Japan cities. (AIArchitect, April4, 2005). According to Ando, although building material is an element which creates space, but it is not the architect's theme. The most important matter is the spaces involved in material. (Jodat, 1996, 58) Ando's interest in raw and unfinished reinforced concrete and natural wooden materials expresses his intention to the Japan traditional architecture such as Ise Temple. In fact the usage of simple materials and forms engage a viewer in an appreciation of architecture, making the piece significant to the person. Ando is therefore in no respect a formalist, his interest in the tangible stems solely from his much deeper concern for their ontological relation to the intangible aspects of architecture. Ando's decision to limit materials and forms comes from the belief that their intrinsic natures heighten the viewer's experience of buildings, especially when they reveal their utmost state of existence.

Seeking Japanese culture and architecture, Ando found a strong source in the Ise Shrine, a severe architecture, set in thick forest, which used to be reconstructed every 20 years, to express a quest for immorality. Ando concentrated on the solemn strength, brevity and abstraction in the use of wood at Ise. On the other hand, his favorite old architecture, Sukiya style, is based on subtle control of nature, concentrating its modes of expression more on surfaces, and tea house is the archetypical example of it. In the consciousness of contemporary Japanese, wood structure is definitely represented by Sukiya and the tea house, and Ando hopes to create a more forceful contemporary expression of it. (Dal Co, 1996, P.468-470)

\section{Sample projects with traditional or ethical insight}

1) Water Temple, 1989-91, Awaji Island:

The temple rises in Hompukuji, a small town in the northern part of Awaji Island, as a collaboration center for Shingon Buddhist Sect.

Few of Tadao Ando's represent the architect's contribution to Japanese culture better than his Water Temple. More than a building, it is a sensorial experience representing a radical change in the old age tradition of Japanese temple architecture. (Image no.8-10)

In terms of form, materials and spatial sequences, the Water Temple is far removed from the classic wooden Buddhist temple, but what Ando's building shares with the traditional temple is a mystic quality of space. Among the bamboo woods, the mountains, the rice paddies and the sea, the temple appears like a pool of lotus flowers enclosed in a thin oval-shaped skin of concrete and sheltered from view by smooth wings of cement. (Image no.11) Its forms enclose important symbols, partly veiled and manifest, rooted in Buddhist doctrine and the most ancient Japanese philosophical tradition. The lotus, symbol of the heavens, refers to the apparition of Amida Buddha, believed to carry a celestial message from the heavens. 
The sensory experience which Ando has designed begins as the visitor approaches the temple and begins to glimpse the smooth surface of the cement wings shielding the pool among the bushes and trees, and a long white gravel path symbolizes the beginning of the purification process believers undergo before they arrive at the sacred place (Domus, 1992).

Ando has taken the oval shape of the pool underground and made it into a sacred enclosure within which he has organized different spaces, dividing the area in two with the long stairway and assigning half of it to the sanctuary and the other half to the adjacent rooms.

The sanctuary is bounded by two semicircular walls enclosing a wooden structure built on the traditional model of Shingon temples, with a statue of Amida Buddha in the centre. (Image no.12) The sacredness of the room is accentuated by the use of color and light; Natural light from a single source filters through a grating behind the statue of the Buddha and floods the nave, warming up the vermilion red in which the room is painted. Furthermore, Ando inspires from Buddha mandala when designing the Temple's plan (Image no.13). Meditation technique is one of the main principals in Shingon sect, that is done by two specific mandalas: Kongo-Kia or World of Diamond-like transparent wisdom, (Image no.14) and Taiko-Kia or World of Womb-like phenomenal experience (Image no.15). Ando's design reminds Kongo-Kia mandala when the blue sky reflects in oval shape of the pool. (Image no.14) Besides the small temple below the lotus pool which has decorated with red color and light, symbolize the World of Womb-like phenomenal experience. (Nitschke, 1993, 62-83, Zanchi, Aug, 2002 )

2) Rokko church, 1986:

The design of Rokko Church, completed in 1986, demonstrates an awareness of traditional spatial manipulation techniques and an ability to use them in contemporary context. Ando's design presents similar characteristics with Shisen- do tomb that was built in 1641 .

A) The passage to the Shinsen-do tomb starts with a smasll entrance at first.

* The first local experience on the passage to the Rokko church is the sensation of entering a mouse hole, and then walking through a dark, complex maze. (It can be defined as a Japanese technique in the beginning of the purification process.)

B) The second phase in Shinsen-do passage is narrow stairs, covered with massive bushes and trees .Because of the narrowness of the passage, the visitors are encouraged to move forward. (Image no.16)

* In Rokko church, phase two describe as a long dim passage framed by a low wall on one side and dense bushes on the other. Enticing the visitors forward is a hazy vision of their destination, fractured by thick branches. The spatial result is that the church seems very far away.

C) Encountering with a hindrance created from plants and changing the passage direction, specifies phase three in Shinsen - do. This part of the passage inspires the difficult access to ultimate destination.

* A U shape stairs down from the end of the straight passage and oblige visitors to veer is the third phase in Ando's church.

D) The fourth phase in Shinsen-do is a small stopping space that is experienced after walking a long distance.

* As visitors down two flights of stairs, turning them first away then back towards it, and deposits them in a stopping space that is semi-circular.

E) The fifth spatial techniques in Shinsen-do is" Repetition" .After passing these phases, visitors reach to the another entrance and the same passage. Thus, they continue their way with a higher stage in spiritual purification. (Image no.17-18)

* At phase five visitors are thrown back to another entrance. The passage repeats when arriving to a glass tunnel. (Image no.19)_

\section{Conclusion}

This article analyzed some projects of the three Japanese pritzker prize winner architects in order to find out the quality of how traditional and ethical design ideas crystallize in the works of contemporary Japanese architects. The results show that the contemporary architects have had good bases for presenting the traditional design concepts (e.g. Ma, Oku and Miegakure.) as standard principals are all formed in the architecture of Japan today. The ethical concepts in different ancient religions especially Shinto and Buddhism, has influenced thoughts of these three architects. Furthermore, project analyses show that Tange has a more formal view point than Maki and Ando. However, Maki pays more attention to the three Japanese spatial Ideas and has more a conceptual look at Japan`s tradition. Herein, Ando has a combination of formal and conceptual look in his designs. He 
presents an innovative experience in spatial composition such as in Water Temple in Awaji where he creates a great transition in Buddhism architecture.

Totally, the methods of linking the Japanese traditional concepts with its contemporary architecture could be addressed in four various dimensions including the following items.

1- Using the ethical concepts and spatial quality such as Oku, Ma and Miegakure.

2- Concerning the traditional Materials and structural details.

3- Space design bases on traditional techniques. These were already used in old temples and gardens.

4- Attending to the methods of environmental connections between city and nature.

Another important issue is the chronological analysis of the three architects' projects with the current architectural styles. Despite Tange was Le Corbusier 's apprentice and that all the three architects were in a way impressed by the works of Le Corbusier, they were successful to keep contacts with Japan traditional design concepts . From 1985 to 1995, these three architects were the winners of Pritzker Prize. In fact during this decade the styles of contemporary Japanese architecture were introduced to the whole world. We can express that the experiences and the methods used by these three architects in linking the past and contemporary architecture of Japan could be a valuable example of how to design according to ones' own traditional architecture and culture.

\section{References}

AIArchitects. (April 4, 2005). Japanese Modernist Master Kenzo Tange.

Architectural Record Symposium. (2004). Technology \& Tradition in contemporary Japanese Architecture, Feb $26,27,28$.

Dal Co Francesco. (1996). Tadao Ando Complete Works. Phaidon Press Limited.

Fumihiko. (Winter. 1994). Investigations in collective Forms. The Japan Architect16. -Maki.

Furuyama Masao. (2005). Analysis of works, thoughts and views of Tadao Ando, translated by H.Mohamadi. Khak publishing Co, Esfehan.

Günter Nitschke. (1993). From Shinto to Ando: Studies in Architectural Anthropology in Japan. Academy Editions. London.

Ishii Kasuhiro. (1990). Impressions of Tepia: an Architectural Monument to its Times. The Japan Architect, v. 65 , no, 8-9.

Jodat M. (1996). Japan's old and contemporary architecture. Aryan publishing co, Tehran.

Kultermann, Udo. (1989). Kenzo Tange: Works and Projects. 1st spanish/english edition. Barcelona: Gustavo Gili, S.A., ISBN 84-252-1400-9. NA1559.T33K83 1989.

Levitt, Brendon. (2005). Veiled Sustainability: The Screen in the Work of Fumihiko Maki

Maki Fumihiko. (Jan.1993). Space Design 93-01, SD No, 340. Kajima Publishing Co, Ltd, Tokyo.

Suzuki, Hiroyuki. (2007). Ministry of Foreign Affairs, Japan. [Online] Available: www.uk.emb-japan.go.jp/en/creativejapan/architecture/index.html (10/16/2007).

TIME in Partnership with CNN. (2008). New Japanese Architect. [Online] Available: www.time.com/time/magazine/article/0,9171,826008-2,00.html (1/10/2008).

www.aia.org/aiarchitect/thisweek05/tw0401/0401 tangeobit.htm accessed in 2007/12/20.

Yu Kishi, Shiro Yoshioka, Miyazaki Hayao \& Miyuki Morita. (2006). "Japaneseness" in transwar Japan: Assimilation and Elimination. International Christian University.

Zanchi Flores. (Aug, 2002). Tadao Ando, Water Temple, Hompuki, Japan, 1989-1991. 


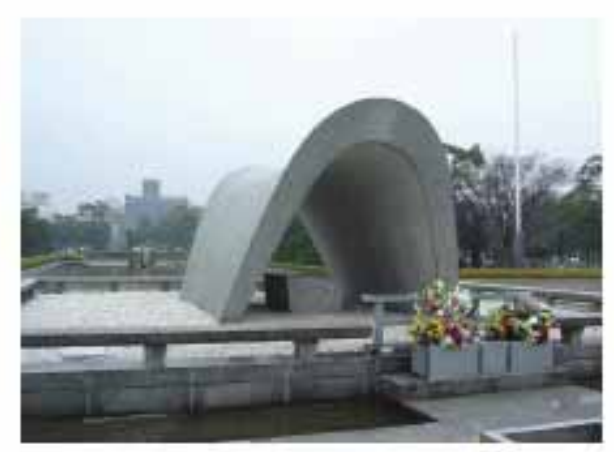

Figure 1. Hiroshima peace memorial

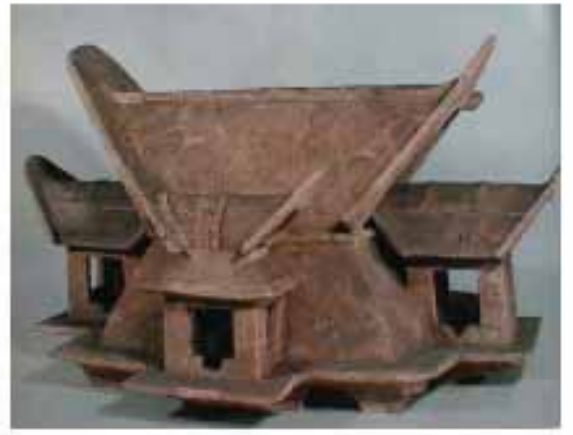

Figure 2. Haniwa traditional tomb

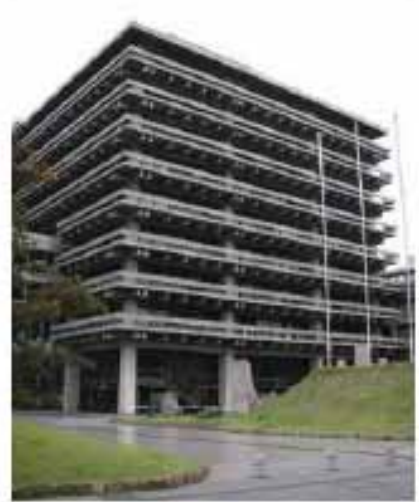

Figure 3. Exposed

Post-and-beam structures

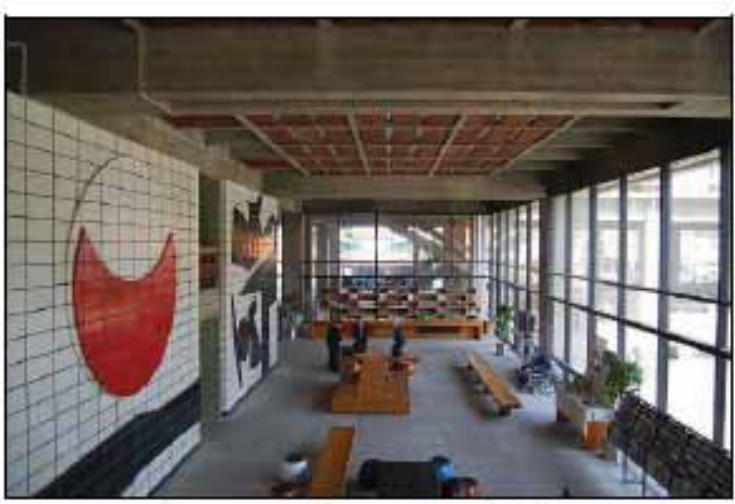

Figure 4. Ceramic with Zen

symbols on the walls

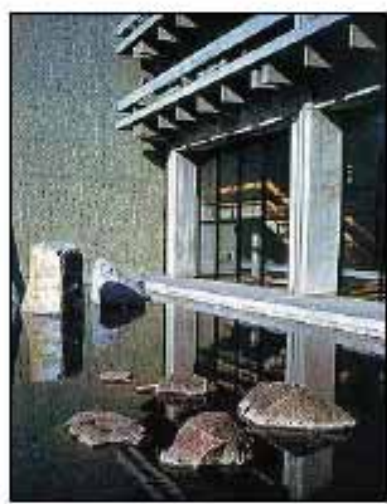

Figure 5 .

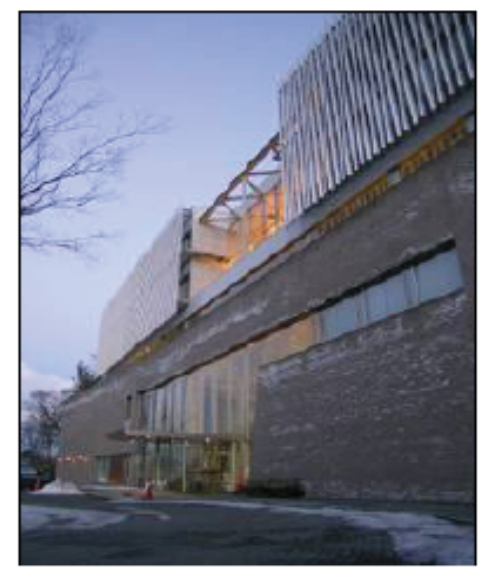

Figure 6. Gender Equality Center, Source: Levitt, Brendon (2005)

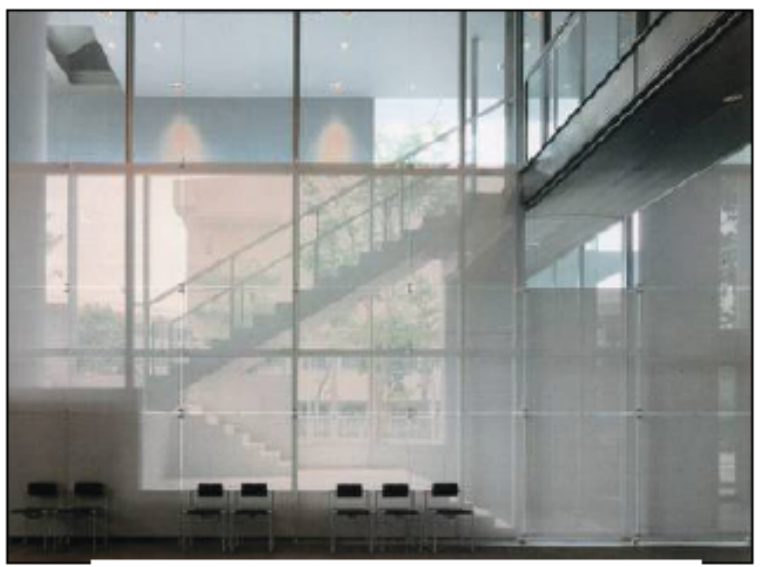

Figure 7. A perforated metal screen filters views in and out of Tepia. (An attempt to express $O k u$ concept) 


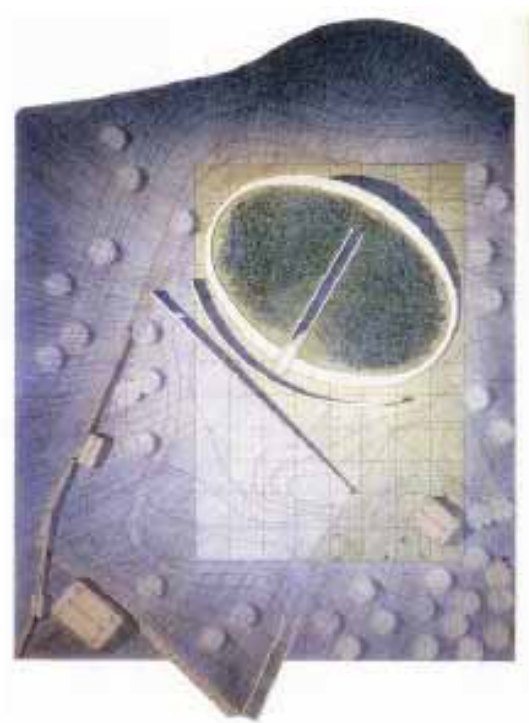

Figure 8. Water Temple plan, Awaji Isl and. Source: www floornature.com

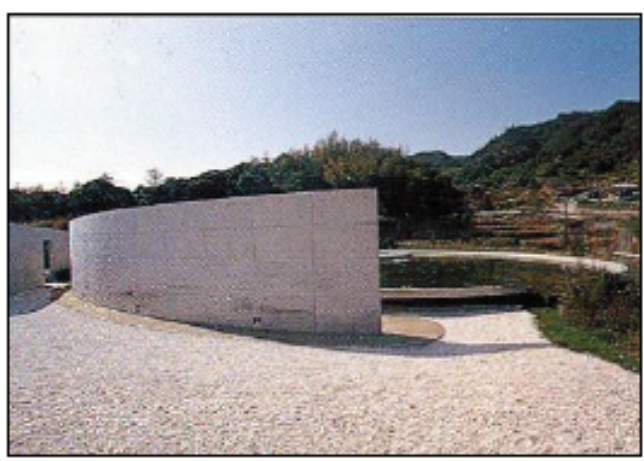

Figure 10. Symbolic entrance situated in concrete wall.

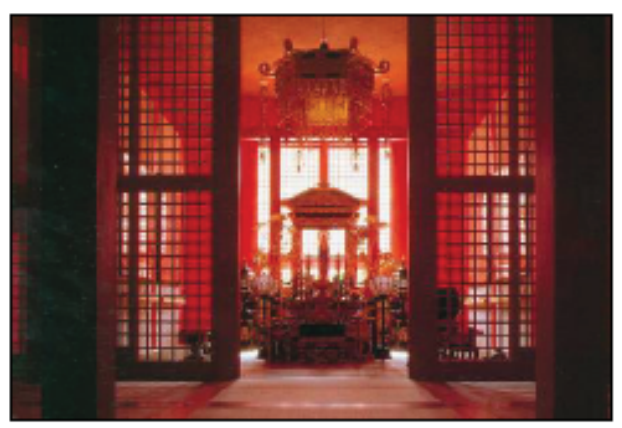

Figure 12. Wooden structure built on the traditional model of Shingon temples

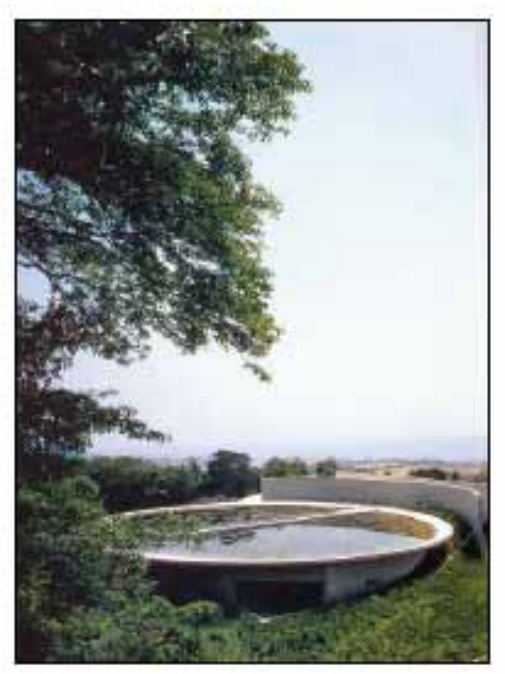

Figure 9. Its forms enclose important symbols, rooted in the ancient Japanese philosophical tradition.

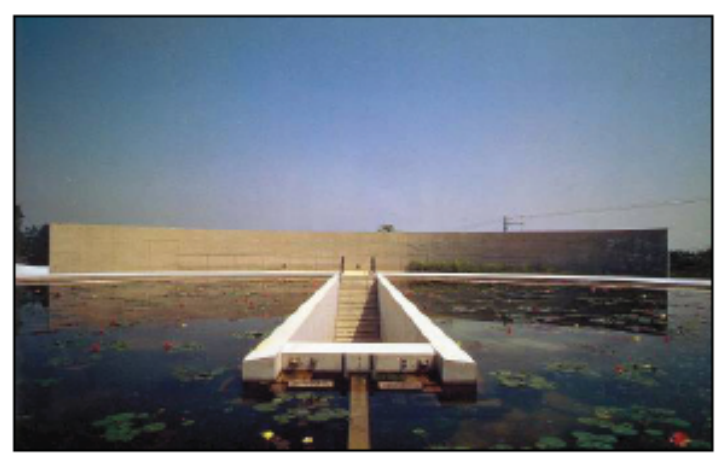

Figure 11. The temple appears like a pool of lotus flowers, symbol of the heaven

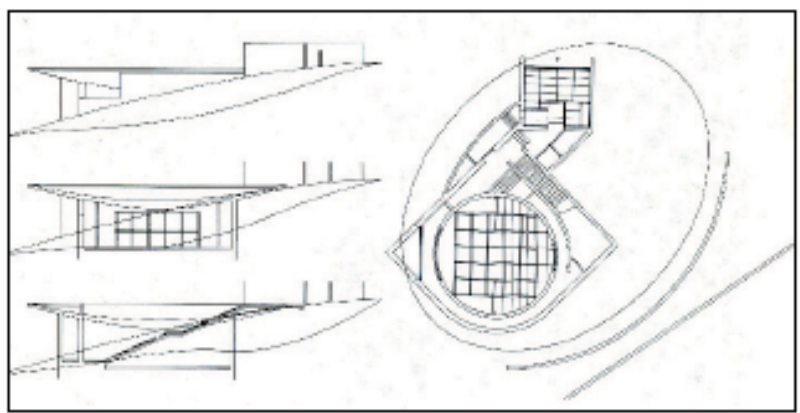

Figure 13. Buddha mandala appears in the Temple's plan. 


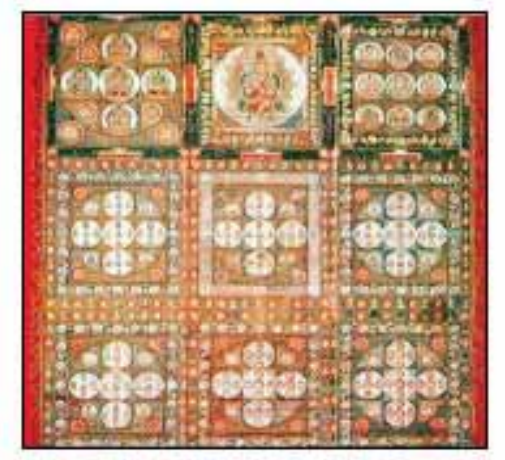

Figure 14. Kongo-Kia mandala, Source: Günter Nitschke, 1993

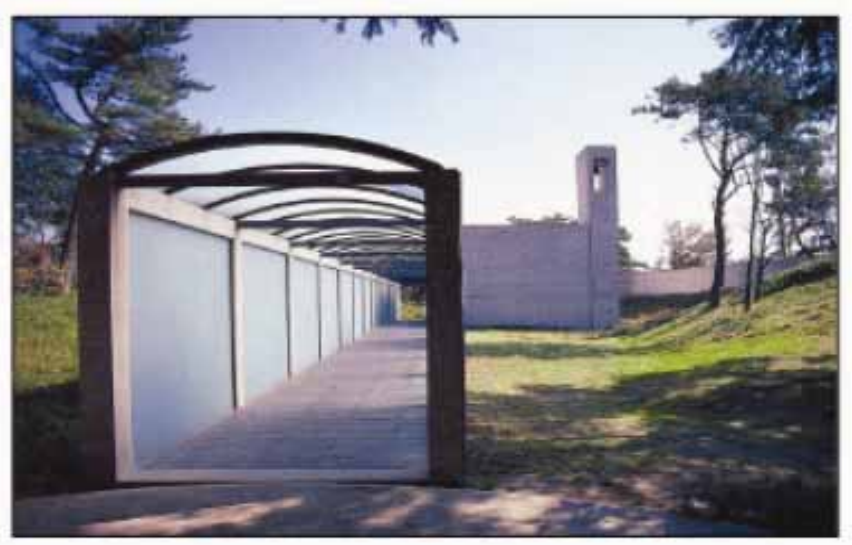

Figure 16. The glass tunnel in Ando's church.

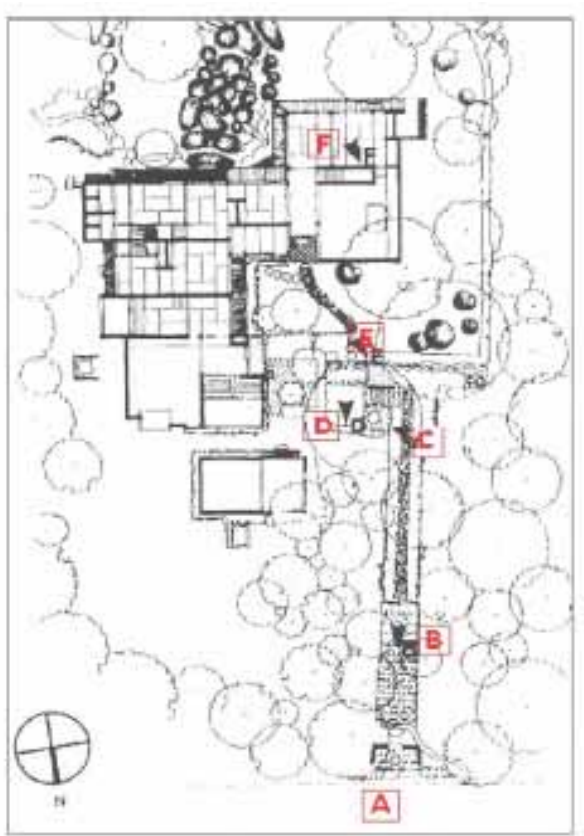

Figure 18. Shinsen - do plan, 1641. Source: Günter Nitschke, 1993

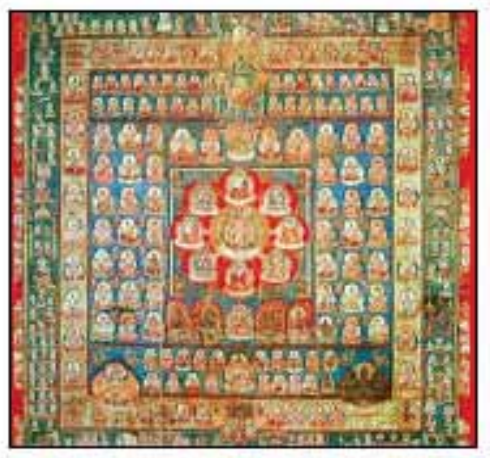

Figure 15. Taiko-Kia mandala

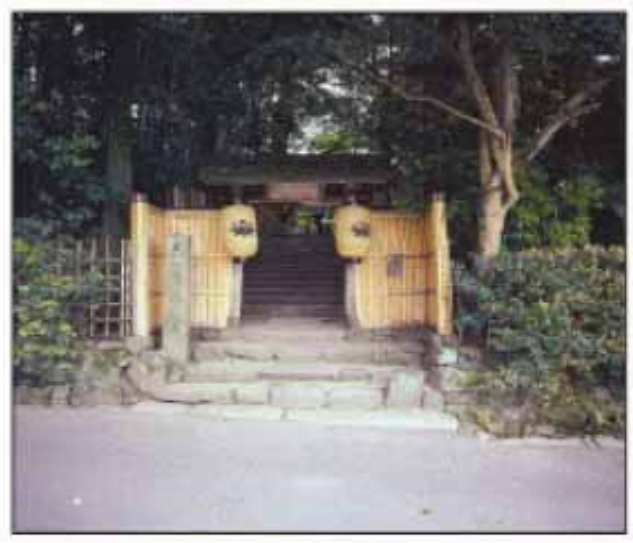

Figure 17. Entrance and the narrow stairs in Shinsen-do tomb.

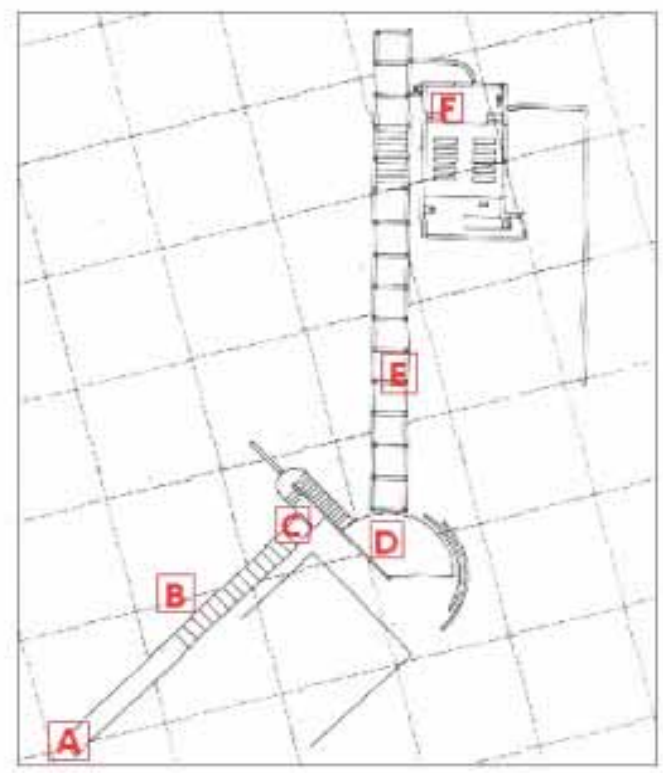

Figure 19. Rokko church plan, 1986. Source: Günter Nitschke, 1993 